\title{
Tripping over tipping points/elements
}

\author{
John A. Glaser
}

Published online: 13 August 2010

(c) US Government 2010

The term "tipping point" has been used to identify a critical threshold susceptible to a tiny perturbation that can qualitatively alter the state or development of a system. "Tipping element" has been introduced to describe largescale components of the Earth system that may pass a tipping point. A special issue of the Proceedings of the National Academy of Science of the United States (PNAS) recently focused on Tipping Elements in Earth Systems has examined potential policy-relevant tipping elements in the climate system with anthropogenic forcing. Subjects such as the evaluation of El Nino/southern oscillation response to global warming, irreversible ice sheet retreat and unstoppable loss, and climate change induced Amazon rainforest dieback were presented in this special issue. An earlier PNAS research article investigated the imprecision of probability assessments of tipping points identified for the global climate system.

The United Nations Environment Program (UNEP) has underscored the importance of land degradation by human activity and the condition of the planet's assessed ecosystems as instances of critical thresholds and tipping points important to the global environment and governments. The UNEP calls global government to establish more environmentally sustainable business practices in response to the concern for these approaching thresholds and tipping points.

Proc Nat Acad Sci 2009, 106(49), 20561-20621; 105(6), 1786-1793; 2008, 106(13), 5041-5046; http://www.unep. org/geo/yearbook/yb2009.

J. A. Glaser $(\bowtie)$

National Risk Management Research Laboratory, US

Environmental Protection Agency, 26 W King Dr,

Cincinnati, OH 45268, USA

e-mail: Glaser.John@epa.gov

\section{Next generation biofuel environmental and sustainability factors}

Assessment of the impacts of next generation biofuels such as dedicated energy crops, forest residues, microalgae, and municipal solid waste was conducted based on literature assessment and limited model evaluation. These next generation technologies were found to be better than conventional biofuels such as corn grain-based ethanol, and soybean-based diesel. Factors used to conduct this evaluation were greenhouse gas emissions, air pollutant emissions, soil health and quality, water use and quality, wastewater, solid waste streams, biodiversity, and land-use changes. This paper summarizes that state-of-knowledge concerning sustainability and environmental factors characteristic of next generation biofuels. The authors admit to a significant uncertainty in the impact estimates as the technology reaches commercial scale. Five general areas of supporting research were identified as: larger field scale trials for each technology, continued research investigating environmental impacts and land-use changes, efficiency optimization of the next generation technologies, investigation of the ultimate health and environmental impacts for each of the technologies, and investigation of trade offs associated with each technologies. New management and decision support tools are also identified as pending needs for technology evaluation.

Environ Sci Technol 2009, 49(13), 4763-4775.

\section{Subsidies favor fossil fuels over renewable energy}

The Environmental Law Institute has conducted a review of US subsidies to energy components for the timeframe of 2002-2008 and presented the results in the 34 page report, 
Estimating U.S. Government Subsidies to Energy Sources: 2002-2008. Subsidies to fossil fuels amounted to $\$ 72$ billion in contrast to $\$ 29$ billion for renewables for the 2002-2008 period. There are significant differences to subsides for the two energy source categories. The fossil fuel subsidy provisions are written into U.S. Tax Code permanent provisions whereas those for renewable energy are limited to fixed time periods which have specified phase-out schedules. Each side of the energy divide has responded to this report in expected ways. It is evident that the current treatment of renewable energy shows a strong bias to fossil fuels which appears to be contrary to current U.S. policy.

http://www.elistore.org/Data/products/d19_07.pdf.

\section{Sustainable energy utilization}

The Journal of the American Chemical Society has introduced JACS Select, the journal's thematic Web-based collections of recently published JACS papers, which highlight and explain topics of interest to a diverse audience. Recently, a Select collection entitled: Harnessing Energy for a Sustainable World was released featuring content from two ACS publications: the Journal of the American Chemical Society and Environmental Science \& Technology. The 21 articles look at structural aspects energy conversions and storage. Just a few items have been selected for comment from the engaging lists of research accounts. Active and less expensive catalysts for the oxygen reduction reaction are important to the commercialization of fuel cell applications for automobiles. Electronics and electric vehicles need environmentally friendly and efficient electrical energy storage devices such as the emerging lithium-ion battery technology. The use of nonenzymatic processes can convert lignocellulosic biomass into organic chemicals such as 5-hydroxymethylfurfural that can be converted into high energy fuels. The conversion of lignocellulosic biomass to methyl halides by the selection of high activity catalyst assists the formation of precursors of alcohols and synthetic gasoline. Carbon footprint analysis permits the understanding of $\mathrm{CO}_{2}$ emissions from different emerging fuel generating activities. All articles will remain free to non-subscribers until the appearance of the next JACS Select.

http://pubs.acs.org/JACSbeta/jvi/issue8.html.

\section{The water crisis}

The importance of water to the population of the planet has been underscored in a recent issue of National Geographic and is assisted through eight related articles: Water is Life, The Big Melt, Sacred waters, The Burden of Thirst, Silent
Streams, California's Pipe Dream, Parting the Waters, and The Last Drop, and a map entitled: World of Rivers. Each article engages the reader through the use of spectacular photography, maps, and figures pertinent to the topic under discussion. A series of pages devoted to relative factoids are sequentially inserted throughout the articles with topics such as where does the water come from, where are the current sources of water such as the $70 \%$ locked in ice, what is the cost of water to each locality, and the use of water in production, i.e., $1 \mathrm{lb}(0.45 \mathrm{~kg})$ of beef requires $1,857 \mathrm{gal}$ $(7,029.51 \mathrm{~L})$ of water, or a pair of blue jeans requires 2,900 gal $(10977.69 \mathrm{~L})$. The issue offers to the reader a sobering analysis of water and its importance to global society. Water touches every aspect of modern society but in vastly different ways depending on the organization of the local society. As we look at the expensive water use for production of commercial articles and food, the obvious question of water conservation appears and begs questions as to how can we become better managers of these very dear environmental assets. The increasing global population only underscores the immediate need for equitable and environmentally sensitive decision making.

Natl Geogr 2010, 217(4), 36-177.

\section{Environmentally benign enzymes}

Multi-copper containing oxidoreductases have been used by nature and synthetic chemists to catalyze the oxidation of a range of low-molecular weight organic compounds.

Laccases or benzenediol: oxygen oxidoreductases are known for their high stability, selectivity for phenols, and mild reaction conditions. A well organized 22 page review article details the distribution of laccases in nature, enzyme structure, catalytic mechanism, and use in organic substrate transformations. The conversion of ferulic acid to vanillin is but one example of phenolic system transformation enabled through the use of laccase enzymes.

Laccases can oxidize phenolic azo dyes leading to the destruction of the azo dye and potential treatment of azo dye bodies in wastewater streams.

The laccase mediated oxidation of 4-methyl-3-hydroxy anthranilic acid leads to condensation of intermediates to form actinocin which is a key component of actinomycin antibiotics. In this case the enzyme is immobilized on polyacrylamide gel.

Adv Synth Catal 2009, 351, 1187-1209.

\section{GE crop analysis}

A two part review of genetically engineered (GE) plants and foods has been assembled in the Annual Reviews of 


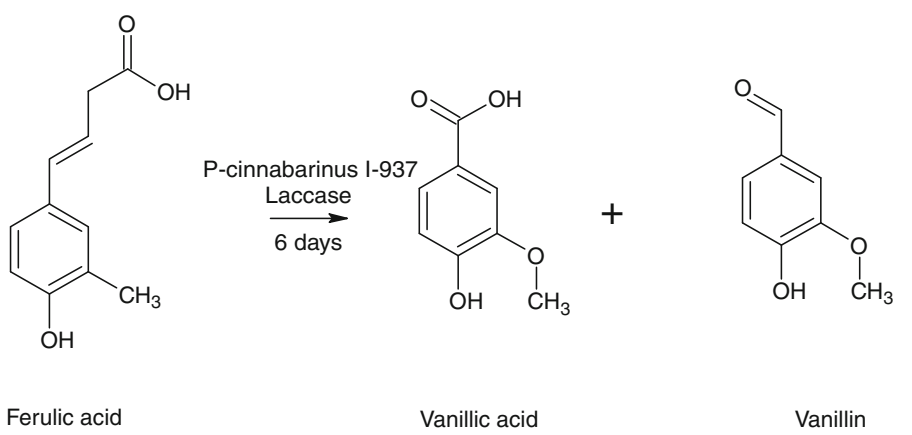<smiles>CC1=CC(=O)C=C(C)C1=O</smiles><smiles>Cc1ccc(C(=O)O)c(N)c1O</smiles>
$\underset{\substack{\text { Immobilized laccase } \\ \text { pH } 5}}{\stackrel{\text { pote buffer }}{\text { posphate }}}$<smiles>Cc1ccc(C(=O)O)c2nc3c(C(=O)O)c(N)c(=O)cc-3oc12</smiles>

Plant Biology in 2008 and 2009. The review is offered by the author as an A Scientist's Analysis of Issues. Part 1 issued in 2008 reviewed general and food issues regarding GE crops. The second half of the review focused on environmental and socioeconomic features of GE crops. Each part of the review is supported by extensive linkages to the scientific literature. The reference lists are highlighted and annotated to provide directive assistance to the most useful literature. Recombinant DNA techniques are identified as a scientific adjunct to traditional breeding techniques by enabling genetic modification and the ability to transfer genes from one kingdom to another thereby leading to significant attribute changes in agricultural crops. Safety evaluations of GE crops and foods must be investigated on a case-by-case basis in the same way crops and foods created by classical breeding and/or mutation technology grown by conventional or organic cultivation means. Clear recognition of the impossibility of a $100 \%$ margin of safety is important. There has been no food safety issues related to GE crop use. For commercial crops, a limited list of crops has been modified using rDNA technology. The installation of different traits, such as pharmaceutical or industrial proteins, requires additional safety and regulatory scrutiny. Peer-reviewed science must be employed in the discernment of safety related to the use of these products. During the decision making process, all information must be employed extending beyond the technical, science-based facts.

Part 2 addresses issues related to environmental and socioeconomic aspects of GE crops and foods. The environmental safety or risk of GE crops is comparable to crops arising from classic breeding techniques. Conservation of global genebanks becomes very important to future crop modifications by classical or genetic breeding techniques. Surveys have shown that pesticide use has accompanied GE crop adoption. The coexistence of different varieties and production methods is important to global agriculture but minimum standards and not zero tolerance for GE traits need to be established for this approach to be realized.

Annu Rev Plant Biol, 2008, 59, 771-812; 2009, 60, 511-559.

\section{Oil sands and sustainability}

The Conference Board of Canada has published a 9 page briefing document entitled: Getting the Balance Right: The Oil Sands, Exporting and Sustainability. The motivation for the document is expressed as whether and how expanded Canadian oil sands production and export can be reconciled with the sustainability agenda. A responsive sustainability agenda is required to social, environmental, 
and economic impacts. The oils sands found in the Canadian province of Alberta are second only to Saudi Arabia as petrochemical/petroleum reserves. The proven reserves of the Alberta oil sands are 173 billion barrels of oil produced through bitumen refining. Current production of oil from oil sands is 1.21 million barrels a day or an annual production of 440 million barrels. Bitumen extraction is conducted by open-pit mining and in situ steam mobilization. Recent production figures show the two extraction methods account for approximately equal volumes of oil. A recent National Geographic issue was identified as portraying the bitumen extraction in poor light. New dry tailings technology is reported to have been introduced to address tailing pond deaths of migratory waterfowl. Land-use frameworks are currently under development by Alberta provincial government. Some land-use recovery has been realized. Land reclamation has been underway for some time but found to be a complex process with several current initiatives. Drillable or in situ steam mobilization is deemed less invasive in the land-use context since only wells and steam generating facility are involved. Water requirements become critical during the winter months. Approaches to water storage are under consideration. The report identifies the amount of GHG's from oil sands production and refinement to be addressable though the use of caps and penalties for each metric ton of bitumen processed. Carbon capture and storage technologies are just beginning to be exploited. The expanding oil sand production will lead to the development of pipelines to the US and one to the Pacific coast to sell to the Chinese market. The report asserts that sustainable exports derived from oil sand are possible but enhanced investment by the producers and governments will be required to improve technologies to meet the needs of the sustainable agenda. A balanced Canadian agenda to address the climate change issues is needed to ensure that the technology meets current global needs in terms of environmental impacts and fuel demands.
Getting the Balance Right: The Oil Sands, Exporting and Sustainability, is available at http://sso.conference board.ca/documents.aspx?did=3379.

\section{Climate decision making uncertainty}

The US Climate Change Science Program has released a very interesting 87 page draft document entitled: Best Practice Approaches for Characterizing, Communicating, and Incorporating Scientific Uncertainty in Climate Decision Making. The report is divided into 9 chapters entitled: Sources and Types of Uncertainty, The Importance of Quantifying Uncertainty, Cognitive Challenges in Estimating Uncertainty, Statistical Methods and Models, Methods for Estimating Uncertainty, Propagation and Analysis of Uncertainty, Making decisions in the Face of Uncertainty, Communicating Uncertainty, and Some Simple Guidance for Researchers. The report asserts that uncertainty is ubiquitous but that does not limit the ability to act. There is a recognized improvement of methods that aid our ability to deal with uncertainty. The report offers a tutorial on climate analysis and decision making while analyzing uncertainty involved with climate-related problems. Semi-technical language is used throughout the report to engage non-expert readers.

http://www.climatescience.gov.

\section{New US chemical policy desired}

A recent article asserts that the fundamental weakness in U.S. chemicals policy has been identified as the lack of adequate protection found with current policies, dissatisfaction with chemicals policy reform, and interdisciplinary research questions demanding attention. Global chemical production is expected to double during the next 24 years, and the priorities of the U.S. chemical enterprise shaped by

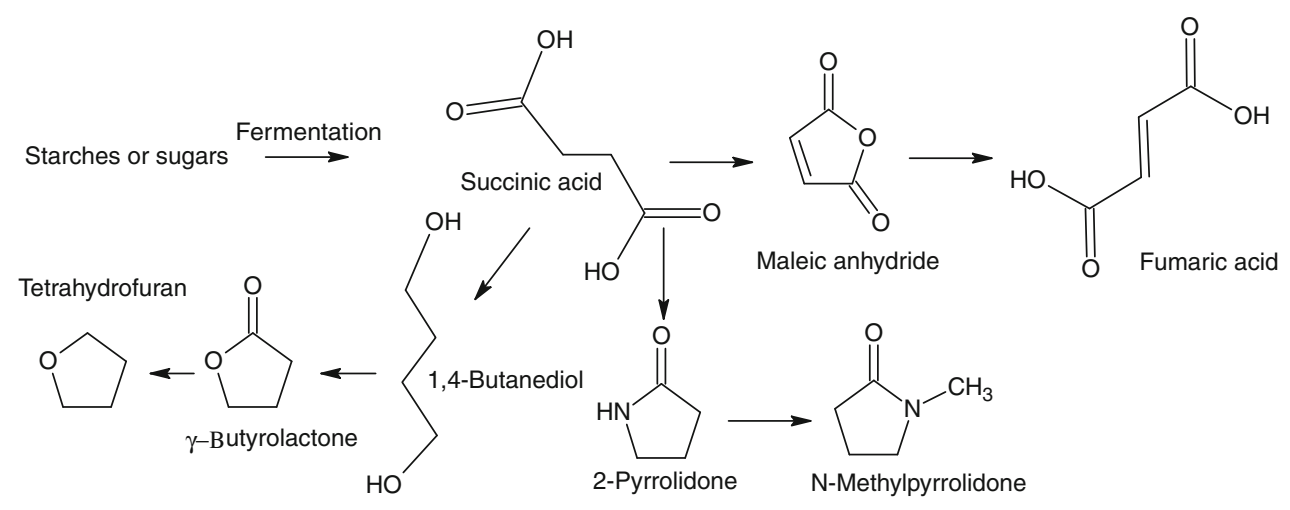

(Green Chem 2009, 11, 13-26) 
federal government policy will be pivotal to the establishment of sustainability in this business sector. Current policies have been found not to adequately protect public health or the environment. Motivation of investment in or scientific exploration of cleaner chemical technologies has yet to be realized. The authors assert that existing policies have produced a U.S. chemicals market which undervalues the safety of chemicals for human health and the environment relative to chemical function, price, and performance. The weaknesses of the Toxic Substances Control Act are criticized for having produced a chemical data gap related to the chemicals' hazard traits to efficiently identify, prioritize, and mitigate the potential health and environmental effects of hazardous chemicals. New technologies such as green chemistry/technology are difficult to introduce due to the lack of incentives derived from policy. Reform to policy can close gaps relative to creating transparency and accountability in the market, are critical to public and environmental health improvement, and stimulating to new technology such as green chemistry. The European Union's REACH (Registration, Evaluation, Authorisation and Restriction of Chemicals) regulation has provided incentives for the United States to make the required changes to policy to enable the injection of new science, and technology.

Environ Health Persp 2009, 117(8), 1202-1209; 117(9), A385-386; Science 2009, 326, 1065-1066.

\section{Environmentally benign catalysts with the succinic acid platform}

The succinic acid platform has been recognized for its organization to produce a variety of organic chemicals from biobased resources. Chemicals available from the synthetic schema of the platform include $\gamma$-butyrolactone, 1,4-butanediol, 2-pyrrolidone, $\mathrm{N}$-methyl pyrrolidone, and tetrahydrofuran. These value-added chemicals can be synthesized from biomass, starches, and sugars but require reduction of precursors through catalytic hydrogenation. Current and past formulations of reaction conditions for catalytic hydrogenation use organic solvents to assist the solubilization of the target organic precursor. It is possible to improve the sustainable characteristics of the hydrogenation step by changing the solvent to a more environmentally benign chemical such as water. With organic solvents the target precursor could be dissolved to form a homogenous solution that was considered important to the desired hydrogenation conditions. Catalyst activity, rate of reaction and completeness of the transformation are each strong modifiers to solvent selection. In the interest of evaluating water compatible catalysts, analogues of Wilkinson and Vaska catalysts were developed using sulfonated forms of the phosphine ligands to assist water solubility. Characterization of the hydrogenation rate, substrate dependency, and reaction mechanism were investigated in several separate publications. Certain substrate specificities and the development of alternate ligand systems continue to be investigated further for potential commercialization candidates. Should this research effort prove to be useful at commercial scale, the environmental impact could be quite large considering the negative impact organic solvents contribute to current technology.

Green Chem 2009, 11, 13-26.

\section{Nanoparticle exposure to humans}

Nanoscience has been recently harnessed to produce nanomaterial items having great benefits in a wide range of applications. With the focus on this newer form of matter, it is important to recognize that there are potential risks too. A recent study of seven female workers (ages 18-47 years) investigated the relation between nanoparticle exposure and human health conditions. The workers were exposed to polyacrylate nanoparticles during a period of 5-13 months. Some of the worker group exhibited shortness of breath, and pleural effusions leading to hospitalization. In depth examination of the workers' lung tissue showed nonspecific pulmonary inflammation, pulmonary fibrosis, and foreign-body granulomas of the pleura. These findings underscore the importance of inhalation protection during long term exposure to nanparticles.

Eur Respir J 2009, 34, 559-567; 35, 222-227.

\section{Nature energy collection}

The journal Nature has often synthesized thematic collections of previously published research papers and news items on specific subject areas. A recent addition to this effort entitled: Energy Collection 2009 has topics of nuclear energy, solar energy, biofuels, wind, and other renewables, and energy efficiency, storage, and transmission. The 50+ items range from news pieces to letters with a few feature articles. Thee collections can offer a quick overview to a topic and leads to follow for more information.

http://www.nature.com/nature/supplements/collections/ energy/. 